\title{
Behavior of RC Beams with Large Openings Subjected to Pure Torsion and Retrofitted by Steel or CFRP Plates
}

\author{
G. M. Hekal ${ }^{1}$ \\ B. A. RAMADAN ${ }^{2}$ N. N. MELEKA ${ }^{1}$ \\ ${ }^{1}$ Assistant professor, Faculty of Engineering, Menoufia University, Egypt. \\ ${ }^{2}$ PhD Student, Faculty of Engineering, Menoufia University, Egypt. \\ ${ }^{3}$ Professor, Faculty of Engineering, Menoufia University, Egypt.
}

\begin{abstract}
Torsion has been considered with an increasingly great importance by structural engineers. Some of the typical cases are space frames, spandrel beams, beams supporting balconies, eccentrically loaded beams, spiral staircases, horizontally curved beams, skew bridges... etc. Transverse openings, in Reinforced Concrete (RC) beams may be essentially required for accommodating utility services in a building structure. Provision of an opening through a beam, however, changes its simple mode of behavior to a more complex one. Therefore, the design of such beams needs special treatment.

Strengthening or retrofitting of concrete structures to compensate the presence of transverse opening not only depends on the applied material but also depends on the used technique. Carbon Fiber Reinforced Polymers (CFRP) plates, provide a more technical alternative to the traditional methods of strengthening in many cases as it gives high strength, low weight, corrosion resistance, easy and quick installation and less changes in structural geometry.

An experimental test program of twenty-one $\mathrm{RC}$ beams with central large openings subjected to pure torsion were strengthened by using additional layers of externally bonded steel or CFRP plates with different techniques. The behaviors of the tested specimens were investigated and compared to identify the effectiveness of each method and material of strengthening to increase the torsional strength of beam with different opening sizes.

The main conclusions and recommendations drawn from the study were discussed and summarized. The research shows that the methods of strengthening by using externally bonded steel strips fixed by eboxy and steel dowels and CFRP plates gave best results.
\end{abstract}

Keywords: Beams, Openings, Torsion, Retrofitting, Steel plates, CFRP, Eboxy, Steel dowels

\section{INTRODUCTION}

Providing an opening in the web of RC beam may be essential to provide a path for required ducts or pipes. However making an opening in the beam web decreases the stiffness of the beam subsequently decreases the resistance for shear, flexure and torsion [1]. Therefore, the presence of transverse opening in a beam, however, changes its simple mode of behavior to a more complex one depending on the location and the dimensions of the opening [2]. The design of such beams needs special treatment, which currently falls beyond the scope of the major building codes [3, 4].

Many openings are required to be provided in the web of the beams after finishing the construction. In this case, it is essential to compensate the reduction of the stiffness by a suitable method to retrofit the beam with its full capacity $[5,6]$.

Many researches concentrate on the shear and bending stresses and some investigate on torsional stresses $[7,8,9,10]$. Equilibrium torsion should be carefully considered in the design because failure of the member is inevitable if it has not adequate torsional strength [11]. Upgrading the stiffness of RC beams of rectangular, $\mathrm{L}$ or $\mathrm{T}$ sections using FRP due to different stresses is investigated by many researches [12,13,14].

In this research, an experimental test program is prepared to study the behavior of reinforced concrete beams with central web openings subjected to pure torsion as well as to investigate and compare some different techniques of strengthening to increase the torsional resistance in the areas around the opening. Nowadays, carbon and glass fiber reinforced polymers (FRP) in the form of strips, rods, plates and wraps woven in one or multi-directions are commonly used for repair and strengthening $\mathrm{RC}$ slabs, shells, beams or columns [15-19]. This attributed to comparatively simple installation and the attractive characteristic such that lightweight, high tensile strength, and immunity to corrosion. 
These advantages have made FRP an attractive choice instead of traditional retrofitting techniques. Field applications over the last years have shown excellent performance of CFRP retrofitted structures. In this research, the strengthening of RC beams with openings was executed by using both steel plates as traditional material or CFRP as an advanced material for the purpose of comparison.

\section{RESEARCH OBJECTIVES}

Sometimes it is necessary to make a hole or a void as a transverse opening in the web of reinforced concrete beam. However providing an opening in the beam decreases the stiffness, which reduces the overall strength of the beam. Limited researches investigate the behavior of beams subjected to torsional stresses. Only very limited literatures are available regarding retrofitting beams with web openings to increase their torsional stiffness. The main object of this research is to determine the efficiency of using different methods and materials as external bonded steel plates and CFRP plates to increase the torsional strength of rectangular reinforced concrete beams with different opening sizes.

\section{EXPERIMENTAL PROGRAM}

Twenty-one typical dimensions and reinforcement of the tested specimens were cast. The specimens were cast in a Z-shaped forms with right angles at its corners. The cross section of the tested beams is $200 \times 300 \mathrm{~mm}$ and $1700 \mathrm{~mm}$ length. The middle part of the specimen is $1300 \mathrm{~mm}$ length.

Five specimens were considered as reference beams without any strengthening and classified in Group 1. One of them has no opening; R0, and the other four reference specimens $\mathrm{R} 30 * 6, \mathrm{R} 30 * 12, \mathrm{R} 60 * 6$, and R60*12 have different opening dimensions; $300 \times 60 \mathrm{~mm}, \quad 300 \times 120 \mathrm{~mm}, \quad 600 \times 60 \mathrm{~mm}$ and $600 \times 120 \mathrm{~mm}$ respectively.

Figure 1 shows the concrete dimensions and reinforcement details of specimen $\mathrm{R} 0$. The concrete dimensions and reinforcement details of specimen with opening $\mathrm{X}^{*} \mathrm{Y}$ is shown in Fig. 2.
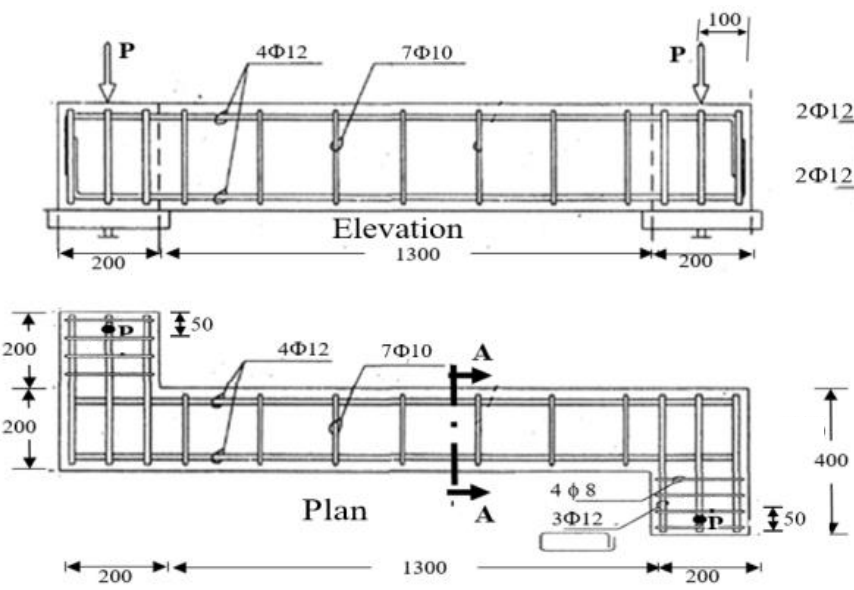

Fig. 1: Dimensions and reinforcment details of refernce specimen without opening R0

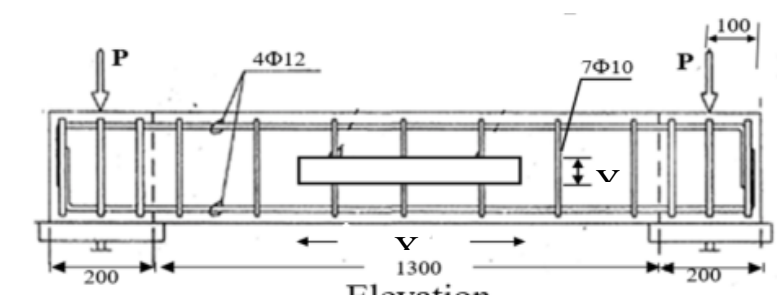

Elevation

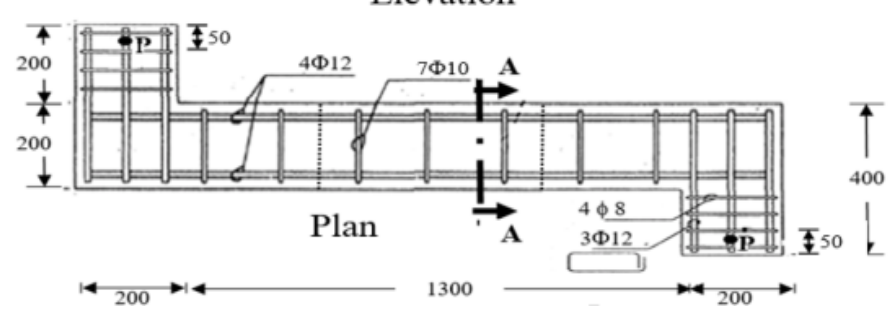

Fig. 2 : Dimensions and reinforcment details of refernce specimen with opening $\mathrm{X}^{*} \mathrm{Y}$

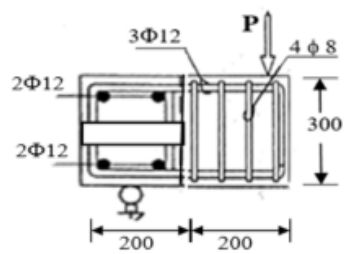

Sec A-A 
The last four reference specimens with openings were replicated four times to form additional sixteen tested specimens. These beams are classified in Groups 2, 3, 4 and 5. In each group, openings were strengthened with different techniques as follows:

Group 2 contains four specimens S30*6, S30*12, $\mathrm{S} 60 * 6$ and $\mathrm{S} 60 * 12$, openings in beams were strengthened using steel plates, $2 \mathrm{~mm}$ thick and 100 $\mathrm{mm}$ width, around the exterior edges of the opening and fixed by Sikadur®-31CF. Figure 3 shows the dimensions of strengthening steel plates in this Group.

Openings in beams of Group 3, were strengthened using the same steel plates of $2 \mathrm{~mm}$ thickness and $100 \mathrm{~mm}$ width, around the exterior edges of the opening fixed by Sikadur®-31CF and also with steel dowels $8 \mathrm{~mm}$ dimeter and $100 \mathrm{~mm}$ long. Figure 4 shows specimens in Group 3; SD30*6, SD30*12, SD60*6 and SD60*12.

Table 1: Experimental test program
In Group 4, openings in beams were strengthened using steel plates, $2 \mathrm{~mm}$ thickness formed as $U$ shape around the interior and exterior edges of the opening welded together to form a box around the opening and fixed by Sikadur ${ }^{\circledR}-31 \mathrm{CF}$ as an epoxy resins as well as by steel dowels $8 \mathrm{~mm}$ dimeter and $100 \mathrm{~mm}$ long. Figure 5 shows specimens in Group 4; SB30*6, SD30*12, SB60*6 and SB60*12.

Group 5 contains beams with openings strengthened using carbon fiber reinforced polymer CFRP plates $1.2 \mathrm{~mm}$ thickness and $100 \mathrm{~mm}$ width, Sika Carbodur@S1012, around the exterior edges of the opening. They were fixed by eboxy Sikadur@-30. Figure 6 shows specimens in Group 5; C30*6, C $30 * 12$, C $60 * 6$ and C60*12.

Table 1 summarizes the details of the experimental test program for each specimens in the different Groups and explains the method of strengthening.

\begin{tabular}{|c|c|c|c|}
\hline Group & $\begin{array}{l}\text { Beam } \\
\text { Code }\end{array}$ & Opening Size & Method of Strengthening \\
\hline \multirow{5}{*}{1} & R0 & No opening & \multirow{5}{*}{$\begin{array}{l}\text { Reference beams } \\
\text { without strengthening }\end{array}$} \\
\hline & $\mathbf{R 3 0} * 6$ & $300 \times 60 \mathrm{~mm}$ & \\
\hline & $\mathbf{R 3 0} * 12$ & $300 \times 120 \mathrm{~mm}$ & \\
\hline & $\mathbf{R 6 0} * 6$ & $600 \times 60 \mathrm{~mm}$ & \\
\hline & $\mathbf{R 6 0 * 1 2}$ & $600 \times 120 \mathrm{~mm}$ & \\
\hline \multirow{4}{*}{2} & $530 * 6$ & $300 \times 60 \mathrm{~mm}$ & \multirow{4}{*}{$\begin{array}{l}\text { Strengthening the central openings by using steel plates, } 2 \mathrm{~mm} \text { thick and } \\
100 \mathrm{~mm} \text { width, around the exterior edges of the opening fixed by } \\
\text { eboxy. }\end{array}$} \\
\hline & $\mathrm{S30} * 12$ & $300 \times 120 \mathrm{~mm}$ & \\
\hline & $560 * 6$ & $600 \times 60 \mathrm{~mm}$ & \\
\hline & $560 * 12$ & $600 \times 120 \mathrm{~mm}$ & \\
\hline \multirow{4}{*}{3} & SD30*6 & $300 \times 60 \mathrm{~mm}$ & \multirow{4}{*}{$\begin{array}{l}\text { Strengthening the central openings by using steel plates, } 2 \mathrm{~mm} \text { thick and } \\
100 \mathrm{~mm} \text { width, around the exterior edges of the opening fixed by } \\
\text { eboxy and steel dowels. }\end{array}$} \\
\hline & SD30 $* 12$ & $300 \times 120 \mathrm{~mm}$ & \\
\hline & SD60*6 & $600 \times 60 \mathrm{~mm}$ & \\
\hline & SD60*12 & $600 \times 120 \mathrm{~mm}$ & \\
\hline \multirow{4}{*}{4} & SB30*6 & $300 \times 60 \mathrm{~mm}$ & \multirow{4}{*}{$\begin{array}{l}\text { Strengthening the central openings by using steel plates, } 2 \mathrm{~mm} \text { thick and } \\
60 \mathrm{~mm} \text { width, around the exterior and interior edges of the opening } \\
\text { fixed by eboxy and steel dowels. }\end{array}$} \\
\hline & SB30*12 & $300 \times 120 \mathrm{~mm}$ & \\
\hline & SB60*6 & $600 \times 60 \mathrm{~mm}$ & \\
\hline & SB60*12 & $600 \times 120 \mathrm{~mm}$ & \\
\hline \multirow{4}{*}{5} & $\mathrm{C} 30 * 6$ & $300 \times 60 \mathrm{~mm}$ & \multirow{4}{*}{$\begin{array}{l}\text { Strengthening the central openings by using CFRP plates as strips } 1.2 \\
\text { mm thick and } 100 \mathrm{~mm} \text { width, around the exterior edges of the opening } \\
\text { fixed by eboxy. }\end{array}$} \\
\hline & $\mathrm{C30} * 12$ & $300 \times 120 \mathrm{~mm}$ & \\
\hline & $\mathrm{C60} * 6$ & $600 \times 60 \mathrm{~mm}$ & \\
\hline & C60*12 & $600 \times 120 \mathrm{~mm}$ & \\
\hline
\end{tabular}




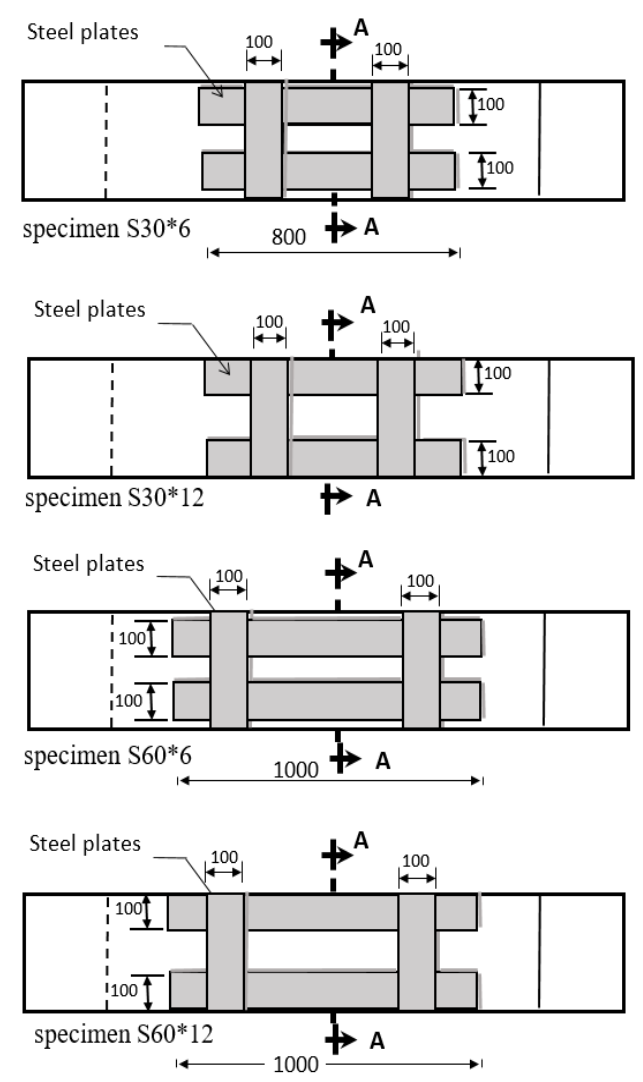

Fig. 3: Strengthening of Group 2
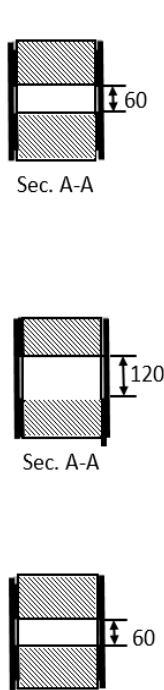

Sec. A-A

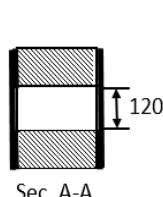

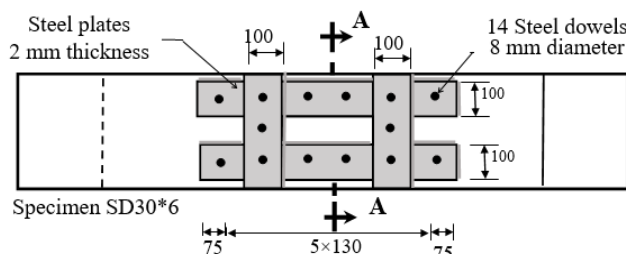
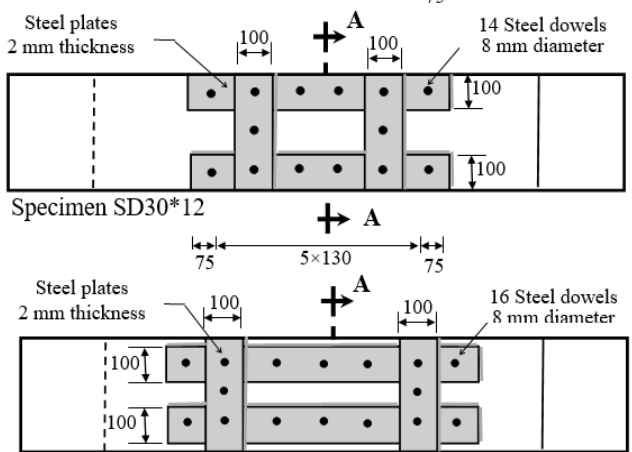

Specimen SD60*6 $\longrightarrow \mathbf{A}$ $|\leftrightarrow| \leftrightarrow \mid \overleftrightarrow{\leftrightarrow}$
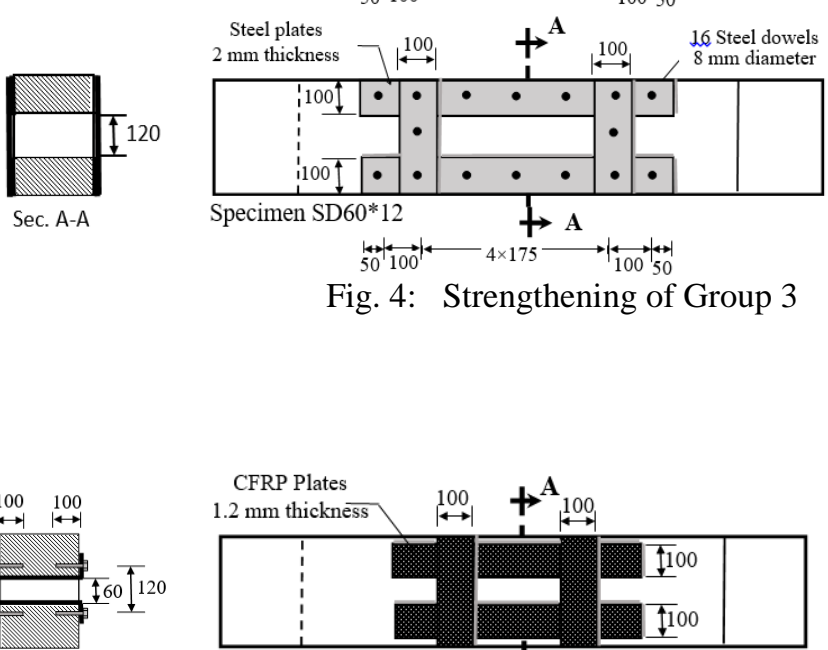

Sec. A-A
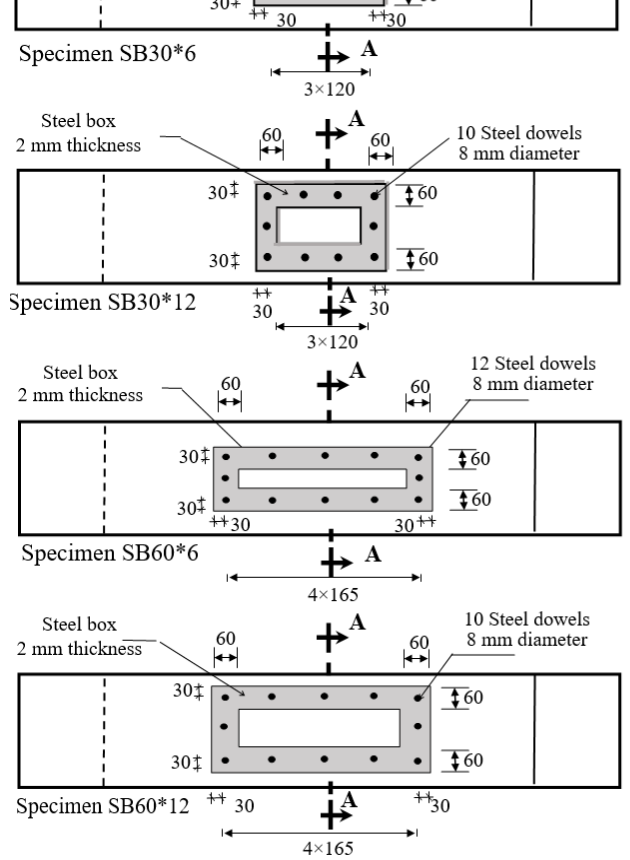

Fig. 5: Strengthening of Group 4
Sec. A-A
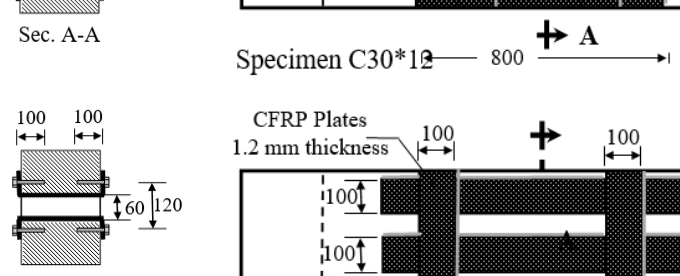

Sec. A-A

CFRP Plates

$1.2 \mathrm{~mm}$ thickness $\quad \stackrel{100}{\leftrightarrow} \quad$ †
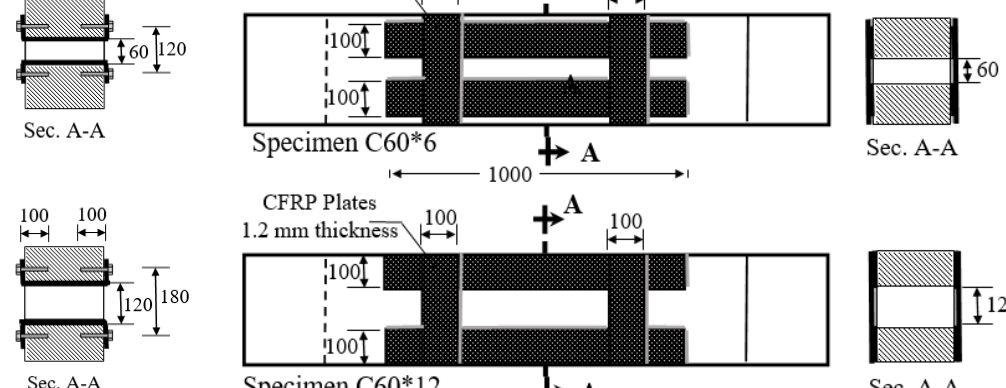

Sec. A-A

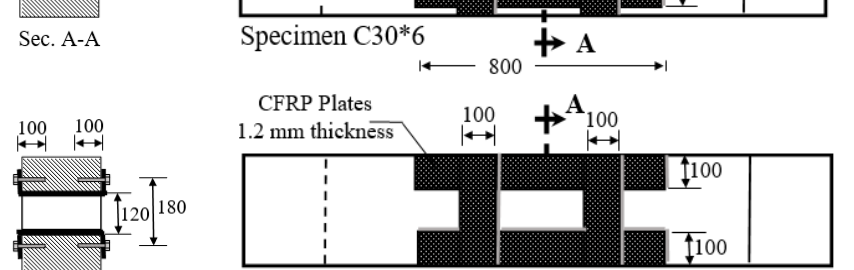
Specimen SD60*12

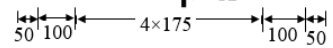

Fig. 4: Strengthening of Group 3
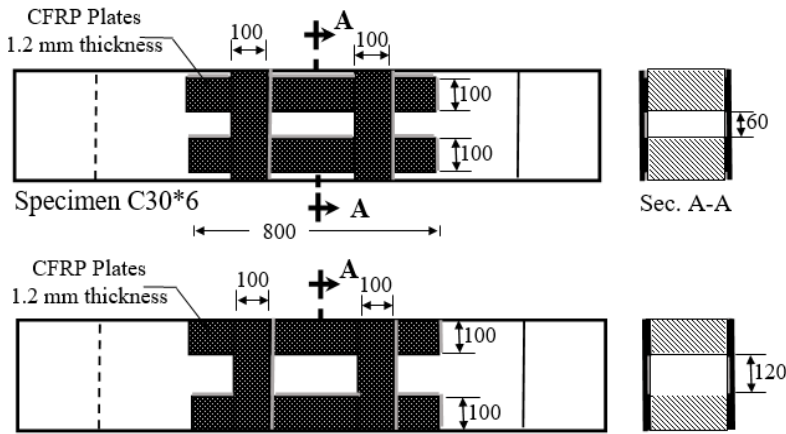

Sec. A-A

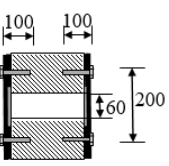

Sec. A-A

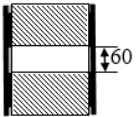

Sec. A-A
CFRP Plates
$1.2 \mathrm{~mm}$ thickness
$\longleftrightarrow 100$

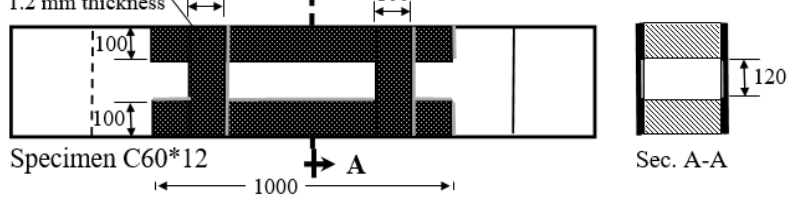

Fig. 6: Strengthening of Group 5 


\section{TEST SET-UP AND INSTRUMENTATION}

The middle part of the specimen, $1300 \mathrm{~mm}$ length, was tested under pure torsion by applying two equal concentrated loads at the center of the two cantilever parts, and $50 \mathrm{~mm}$ form each end as shown in Figs. $(1,2)$. These cantilevers were designed to resist the maximum shearing and bending moments that would take place during testing. The loading rig is shown in Fig. 7. Loads were applied in increments using a hydraulic jack of 50 ton maximum capacity. Deflections under the concentrated loads, angle of twist, first cracking loads and ultimate failure loads were recorded. Propagation of cracks was marked

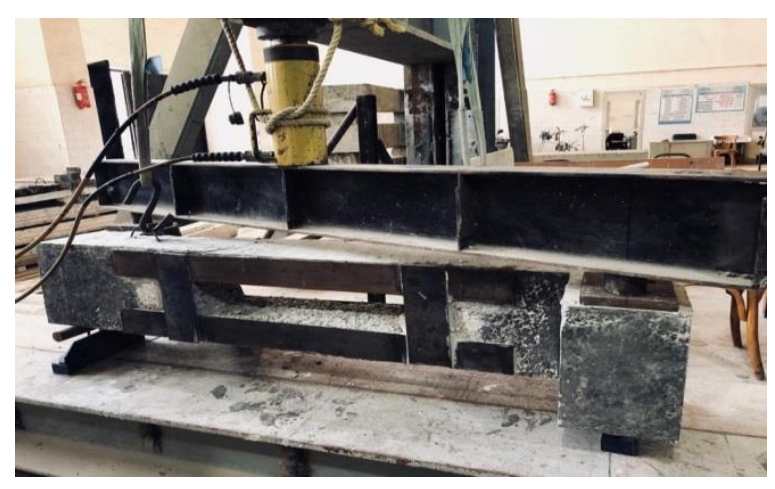

after each load increment up to failure. Dial gauges of $0.01 \mathrm{~mm}$ accuracy and total capacity of $20 \mathrm{~mm}$ were used for measuring deflections under the concentrated loads.

Table 2 defines concrete mix proportions and compressive strength after 7 and 28 days.

Table 3 shows the mechanical properties of steel reinforcement and strengthening steel plates and Table 4 identify the mechanical properties of CFRP plates (Sikadur@ Plates) [20].

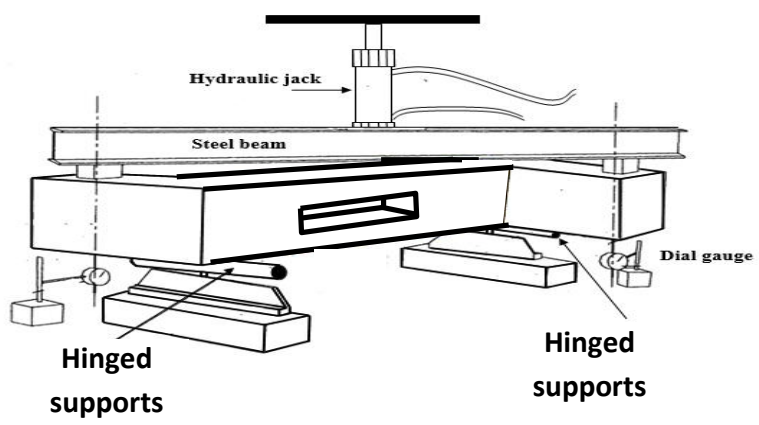

Fig. 7: Test set up and instrumentation

Table 2: Concrete mix proportions and compressive strength

\begin{tabular}{|c|c|c|c|c|c|c|c|c|c|c|}
\hline \multirow{2}{*}{$\begin{array}{l}\stackrel{0}{z} \\
\dot{x} \\
\dot{z}\end{array}$} & \multicolumn{4}{|c|}{$\begin{array}{l}\text { Mix proportions } \\
\mathrm{kg} / \mathrm{m}^{3}\end{array}$} & \multirow{2}{*}{ 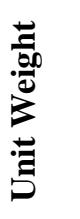 } & \multirow{2}{*}{ 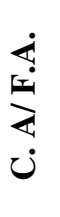 } & \multirow{2}{*}{$\frac{d}{3}$} & \multirow{2}{*}{ 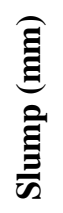 } & \multicolumn{2}{|c|}{$\begin{array}{c}\text { Compressive Strength } \\
\mathrm{kg} / \mathrm{cm}^{2}\end{array}$} \\
\hline & C & $\mathbf{W}$ & F.A & C.A & & & & & $\begin{array}{l}7 \text { days } \\
\mathrm{kg} / \mathrm{cm}^{2}\end{array}$ & $\begin{array}{l}28 \text { days } \\
\mathrm{kg} / \mathrm{cm}^{2}\end{array}$ \\
\hline 1 & 350 & 157.5 & 640 & 1278 & 2426 & 2 & 45 & 32 & 235 & 303 \\
\hline
\end{tabular}

Where: $\mathrm{C}=$ Portland cement from Suez Company

$\mathrm{W}=$ Water $\quad$ F. A. = Fine aggregate

C. A. = Coarse aggregate (crushed dolomite with a nominal maximum size of $25 \mathrm{~mm}$ )

Table 3: Mechanical properties of steel reinforcement and strengthening plates

\begin{tabular}{|c|c|c|c|c|}
\hline Steel Type & $\begin{array}{l}\text { Yield Stress } \\
\left(\mathrm{kg} / \mathrm{cm}^{2}\right)\end{array}$ & $\begin{array}{c}\text { Tensile } \\
\text { Strength } \\
\left(\mathrm{kg} / \mathrm{cm}^{2}\right)\end{array}$ & $\begin{array}{c}\text { Elongation } \\
\%\end{array}$ & $\begin{array}{c}\text { Modulus of Elasticity } \\
\left(\mathrm{kg} / \mathrm{cm}^{2}\right)\end{array}$ \\
\hline High Tensile & 3650 & 5320 & 15.0 & 2100000 \\
\hline Mild Steel & 2530 & 3730 & 21 & 2020000 \\
\hline Steel Plates & 2250 & 2400 & 23 & 2100000 \\
\hline
\end{tabular}

Table 4: Mechanical properties of CFRP plates (Sikadur® Plates) [20]

\begin{tabular}{|l|c|}
\hline \multicolumn{1}{|c|}{ Property } & $\begin{array}{c}\text { CFRP } \\
\text { Sikadur® S1012 }\end{array}$ \\
\hline Width, mm & 1.2 \\
\hline Plate width, mm & 100 \\
\hline Density, g/cm ${ }^{3}$ & 1.6 \\
\hline Tensile E-Modulus, $\mathrm{MPa}$ & $165000 \quad\left(1682531 \mathrm{~kg} / \mathrm{cm}^{2}\right)$ \\
\hline Tensile strength, MPa & Min. value $=2800\left(28550 \mathrm{~kg} / \mathrm{cm}^{2}\right)$ \\
\hline Strain at break & Min. Value not less than $1.7 \%$ \\
\hline
\end{tabular}




\section{EXPERIMENTAL RESULTS}

All tested reference beams in Group 1 failed due to pure torsion. Typical cracking of strengthened beams were observed. Diagonal cracks were propagated forming a spiral trajectory on the four sides of the span as expected [21].

Figure 8 shows the crack pattern for reference specimen in Group 1. First diagonal cracks for R0 were recorded at load 4 ton. It is noticed that diagonal cracks spread along the span.

The first cracking loads for specimen R30*6, $\mathrm{R} 30 * 12, \mathrm{R} 60 * 6$ and $\mathrm{R} 60 * 12$, were $2,1.8,1.6$ and 1.5 ton respectively. It is noticed that openings reduced the torsional rigidity as a results of rapid cracking [22]. Diagonal cracks spread at the mid span along the length of the openings and passes at their corners.

Figure 9 shows the crack patterns for strengthened beams by steel plates fixed by eboxy only in Group 2 . The first cracking loads for specimen S30*6, S30*12, $\mathrm{S} 60 * 6$ and $\mathrm{S} 60 * 12$ were $3,2.8,2.2$ and 2.0 ton respectively. Two diagonal cracks spread diagonally from the ends of the openings 300x60 and 300x120 $\mathrm{mm}$ respectively while only one diagonal crack starts at one corner of the opening and directed to the mid length in case of openings $600 \times 60$ and $600 \times 120 \mathrm{~mm}$.
Figure 10 shows the crack patterns for beams strengthened by steel plates fixed by eboxy and steel dowels in Group 3. The first cracking loads for specimen $\mathrm{SD} 30 * 6, \mathrm{SD} 30 * 12, \mathrm{SD} 60 * 6$ and SD60*12 were 5, 4.4, 4.0 and 3.5 ton respectively. For specimen SD30x6 cracks spread along the span as R0. For other specimens in this Group. Only one diagonal crack starts at one corner of the opening and directed to the mid length.

Figure 11 shows the crack patterns for strengthened beams by steel boxes fixed by both eboxy and steel dowels in Group 4. The first cracking loads for specimen SB30*6, SB30*12, SB60*6 and SB60*12 were $4.8,3.2,2.2$ and 2.0 ton respectively. Two diagonal cracks spread diagonally from the ends of the openings 300x60 and 300x120 mm respectively while only one diagonal crack starts at one corner of the opening and directed to the mid length in case of openings 600x60 and 600x120 mm.

Figure 12 shows the crack patterns for strengthened beams by CFRP plates by eboxy in Group 5 . The first cracking loads for specimen $\mathrm{C} 30 * 6, \mathrm{C} 30 * 12, \mathrm{C} 60 * 6$ and $\mathrm{C} 60 * 12$ were $7.4,6.2,5.0$ and 4.0 ton respectively. For all specimens in this group, only one diagonal crack starts at one corner of the opening and directed to the mid length.

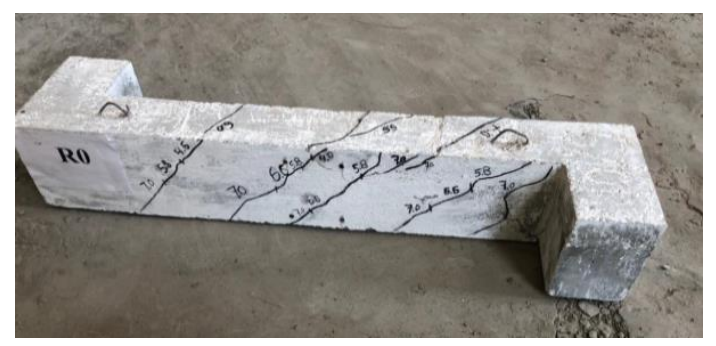

(a) Crack pattern for beam $\mathrm{R} 0$

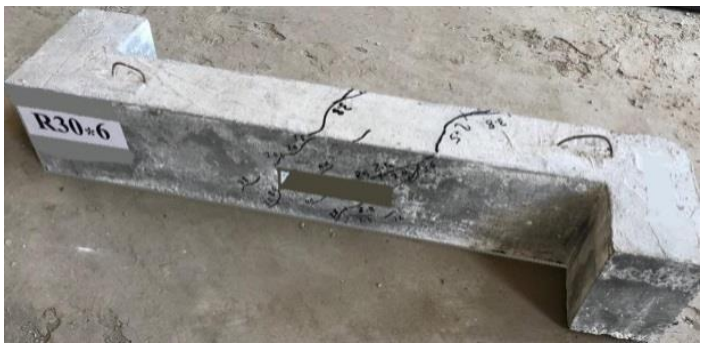

(b) Crack pattern for R30*6

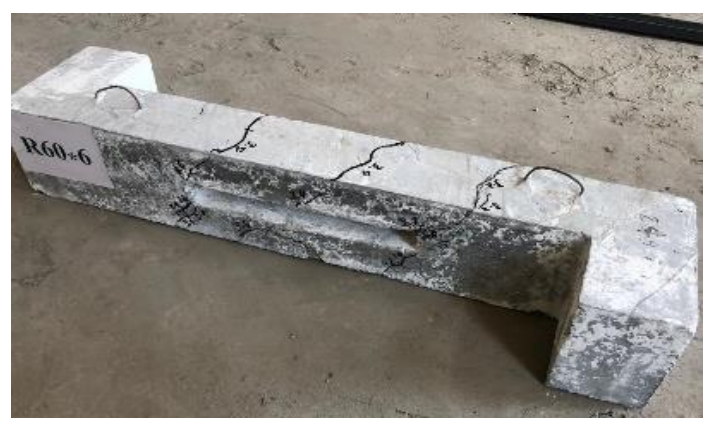

(d) Crack pattern for $\mathrm{R} 60 * 6$

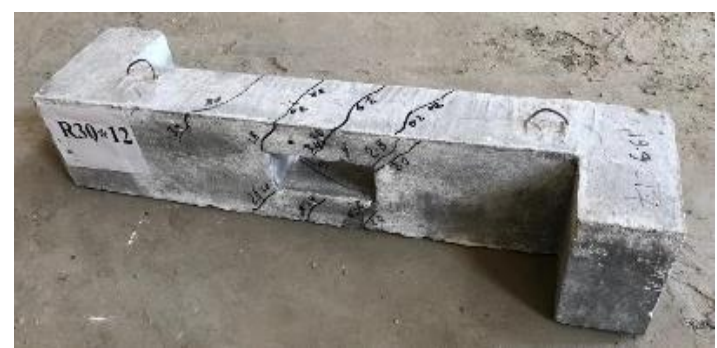

(c) Crack pattern for R30*12

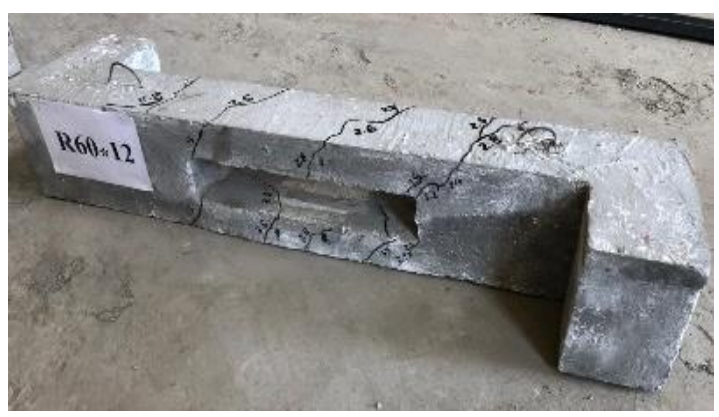

(e) Crack pattern for R60*12

Fig. 8: Crack pattern for reference specimens in Group 1 


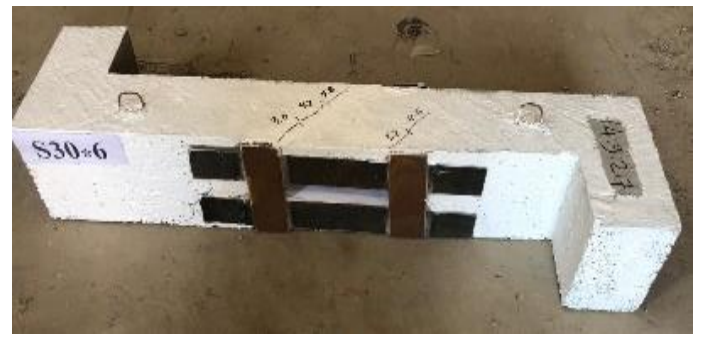

(a) Crack pattern for S30x6

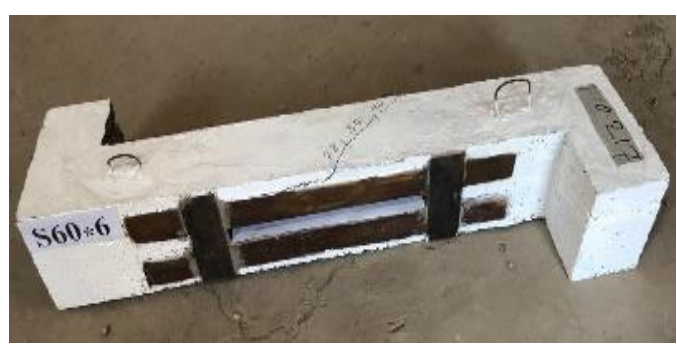

(c) Crack pattern for S60x6

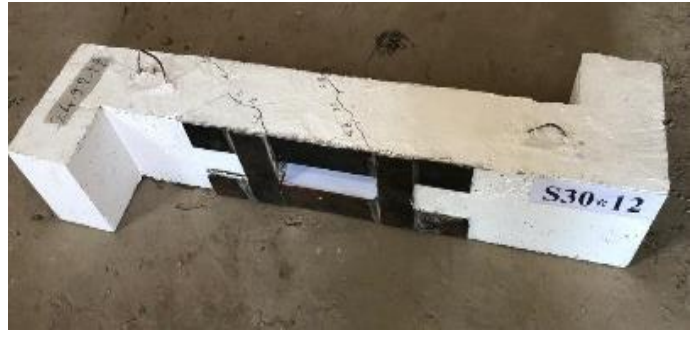

(b) Crack pattern for S30x12

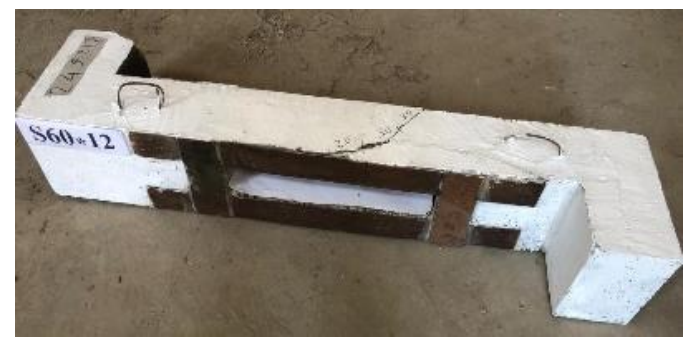

(d) Crack pattern for S60x12

Fig. 9: Crack pattern for Group 2

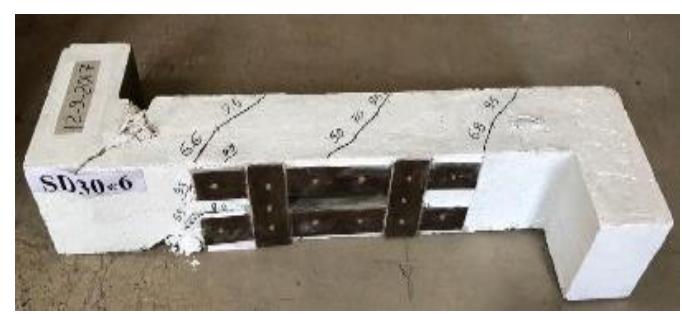

(a) Crack pattern for SD30x6

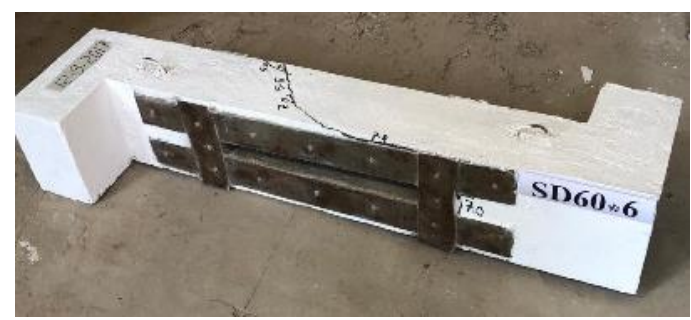

(c) Crack pattern for SD60x6

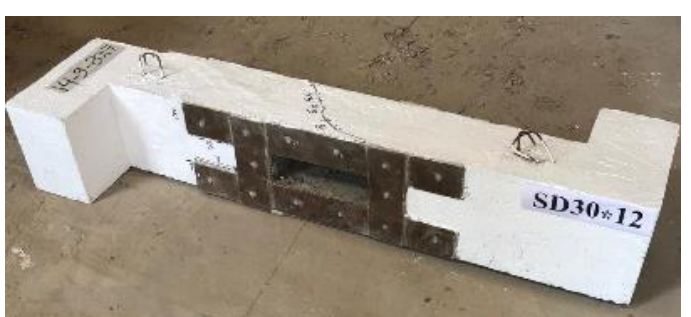

(b) Crack pattern for SD30x12

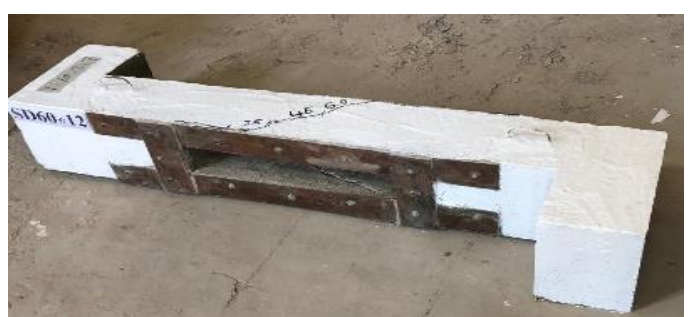

(d) Crack pattern for SD60x12

Fig. 10: Crack pattern for Group 3

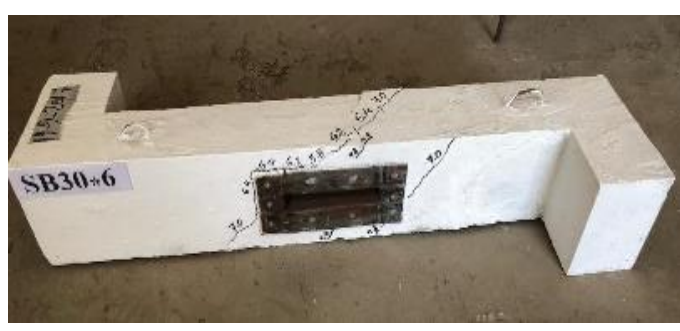

(a) Crack pattern for SB30x6

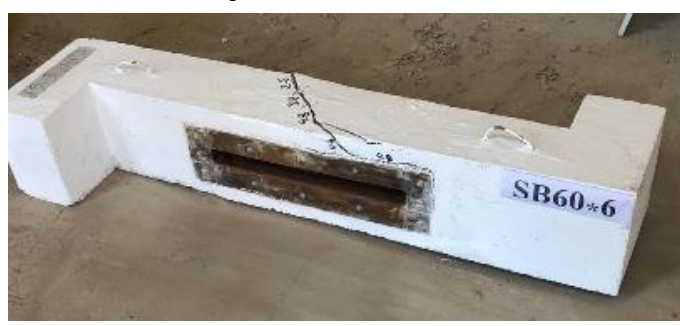

(c) Crack pattern for SB60x6

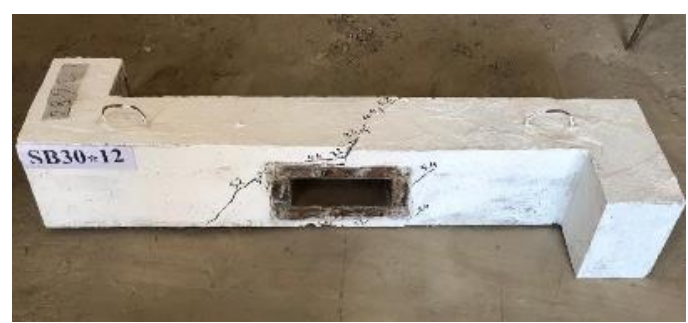

(b) Crack pattern for SB30x12

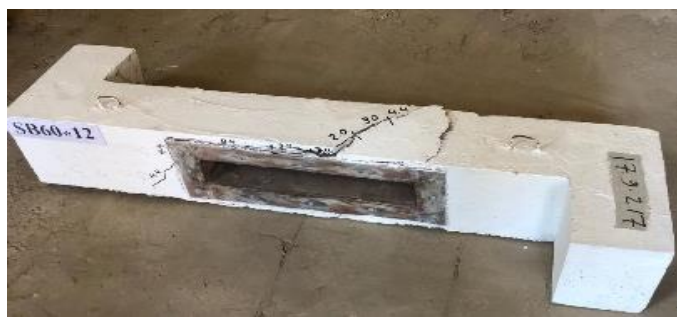

(d) Crack pattern for SB60x12

Fig. 11: Crack pattern for Group 4 


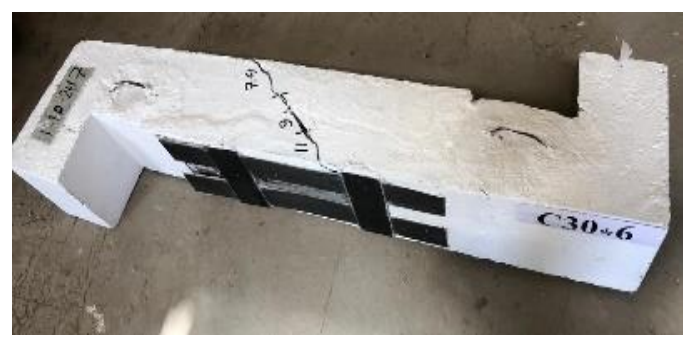

(a) Crack pattern for $\mathrm{C} 30 \mathrm{x} 6$

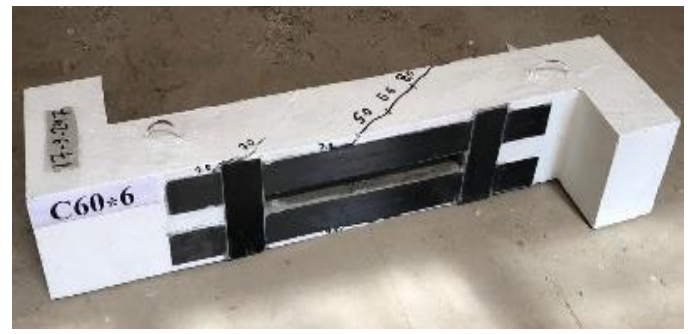

(c) Crack pattern for C60x6

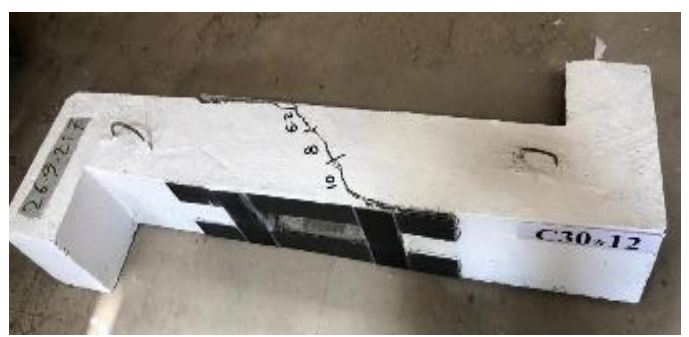

(b) Crack pattern for $\mathrm{C} 30 \times 12$

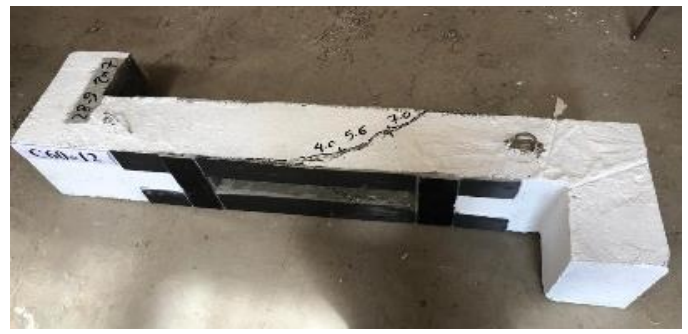

(d) Crack pattern for $\mathrm{C} 60 \times 12$

Fig. 12: Crack pattern for Group 5

For reference beams in Group 1, ultimate torque decreased for specimens R30*6, R30*12, R60*6, and $\mathrm{R} 60 * 12$ due to opening with respect to R0 by about $43 \%, 51 \%, 51 \%$ and $60 \%$ respectively. It is noticed from this results that beams with the same area of openings $300 \times 120 \mathrm{~mm}$ and $600 \times 60 \mathrm{~mm}$ decreased the torsional strength with the same percent.

In Group 2, ultimate torques for S30*6, S30*12, $\mathrm{S} 60 * 6$ and $\mathrm{S} 60 * 12$ increased with respect to the corresponding reference specimens R30*6, R30*12, $\mathrm{R} 60 * 6$ and $\mathrm{R} 60 * 12$ by about $40 \%, 40 \%, 16 \%$, and $23 \%$ respectively. This method of strengthening was more effective in larger depths and smaller breadths.

Using steel dowels to fix the steel plate in addition to the eboxy in Group 3 improved the results. The ultimate torques for SD30*6, SD30*12, SD60*6 and SD60*12 were increased with respect to the corresponding reference specimens R30*6, R30*12, $\mathrm{R} 60 * 6$ and $\mathrm{R} 60 * 12$ by about $138 \%, 133 \%, 105 \%$, and $131 \%$ respectively. Ultimate torques for SD30*6, SD30*12, SD60*6 and SD60*12 were improved with respect to specimens $\mathrm{S} 30 * 6, \mathrm{~S} 30 * 12, \mathrm{~S} 60 * 6$ and S60*12 by about $70 \%, 67 \%, 76 \%$, and $88 \%$ respectively. It is noticed that using dowels in addition to eboxy improved the results effectively in torsion as dowels resist part of the induced shear flow near the surfaces of the openings where the concrete cover subjected to the main stresses of torsion [23]. More number of steel dowels improved the torsional strength of specimen with opening of the same area $300 \times 120 \mathrm{~mm}$ and $600 \times 60 \mathrm{~mm}$. It is noticed also that specimens SD30*6 and SD30*12 gave better results than the reference beam R0 by about $35 \%$ and $14 \%$ respectively. The improvement depended on the size of openings. The increase of the opening dimensions decreases the effects of the strengthening. near the surfaces of the openings where the concrete cover subjected to the main stresses of torsion [23]. More number of steel dowels improved the torsional

$300 \times 120 \mathrm{~mm}$ and $600 \times 60 \mathrm{~mm}$. It is noticed also that specimens SD30*6 and SD30*12 gave better results than the reference beam R0 by about $35 \%$ and $14 \%$ respectively. The improvement depended on the size of openings. The increase of the opening dimensions decreases the effects of the strengthening.

In Group 4, the ultimate torques for SB30*6, SB30*12, SB60*6 and SB60*12 were increased with respect to the corresponding reference specimens $\mathrm{R} 30 * 6, \mathrm{R} 30 * 12, \mathrm{R} 60 * 6$ and $\mathrm{R} 60 * 12$ by about $76 \%$, $58 \%, 40 \%$, and $57 \%$ respectively. These improvements were less than the improvements of Group 3, and this may be attributed to the reduction of the area of strengthening steel plates used on the external surfaces. Using this technique of steel box in $\mathrm{U}$ shape around the internal sides of opening gave better results for resisting bending stresses with respect to using external steel plates around the opening. Less effects of this type of strengthening were noticed for resisting torsion as the main stresses for torsion concentrate on the external surfaces of the cross section of the beam.

Using carbon fiber reinforced polymer CFRP plates fixed by eboxy in Group 5 improved the results. The ultimate torques for $\mathrm{C} 30 * 6, \mathrm{C} 30 * 12, \mathrm{C} 60 * 6$ and C60*12 were increased with respect to the corresponding reference specimens R30*6, R30*12, $\mathrm{R} 60 * 6$ and R60*12 by about $176 \%, 167 \%, 133 \%$, and $151 \%$ respectively. These improvements are considered the best results with respect to the other methods of strengthening of the test results. It is noticed also that strengthening with carbon plates fixed by eboxy improved the torsional strength for all specimen more than the reference beam R0. 
Specimens C30*6, C30*12, C60*6 and C60*12 gave better results than beam R0 by about $57 \%, 31 \%, 14 \%$ and $0.0 \%$ respectively. The improvement depended on the size of openings. The effect of strengthening increased with the increase of the opening dimensions. This may be attributed to using more lengths of carbon plates. So this technique is recommended for large openings.

Figure 13 compares cracking and ultimate torques of all tested strengthened beams with respect to their reference beams.

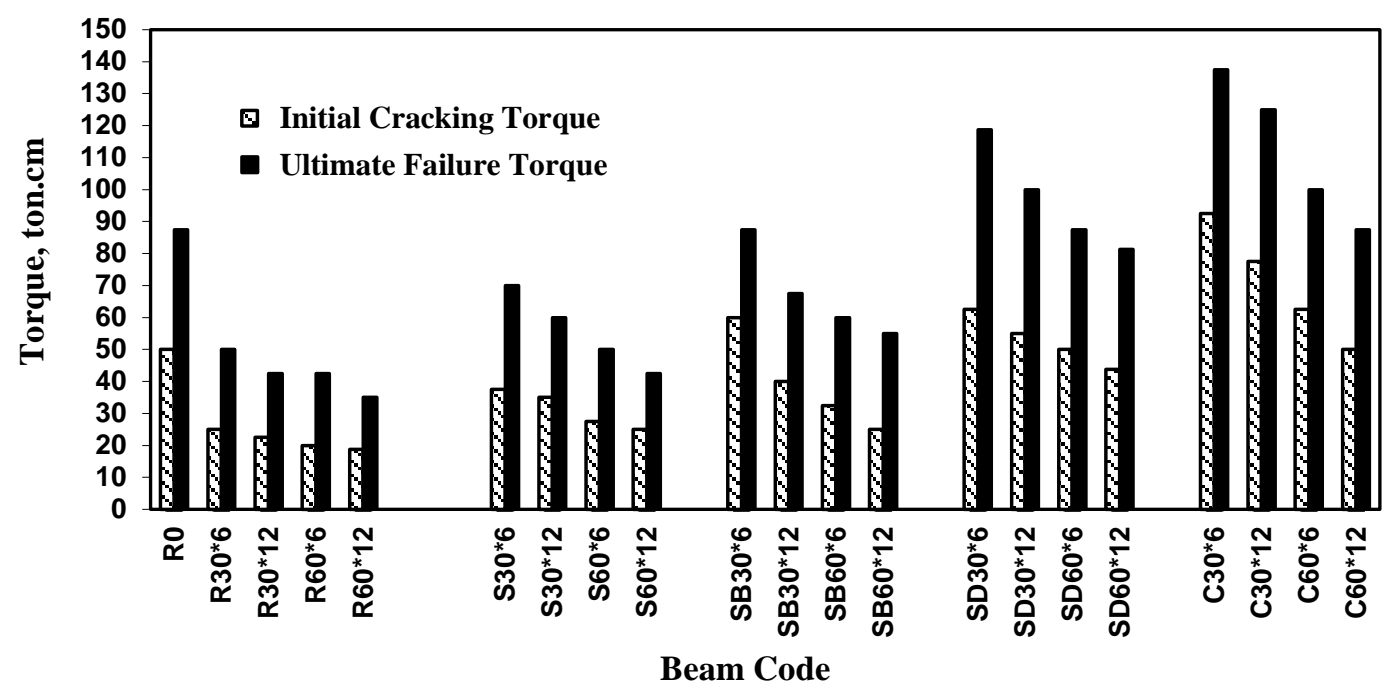

Fig. 13: Cracking and ultimate torques of all tested beams

\section{TWISTING ANGLES}

Ductility of beams subjected to torsion can be defined as the ratio between the maximum twisting angle due to the ultimate torque and the maximum twisting angle at the first cracking load. Energy absorption is always defined as the area under the torque-twisting angle curve until failure.

Figure 14 shows torque versus twisting angle curves for reference reinforced concrete beams. It shows the reduction of torsional strength as well as the reduction in energy absorption due to different sizes of openings with respect to the beam without opening, R0. The reduction increased with the increase of the opening area. Figure 15 shows torque versus twisting angle curves for Group 2. It shows a moderate increase in the torsional strength and ductility. Best result for this group obtained for $\mathrm{S} 30 * 6$ which approaches the behavior of R0.
Figure 16 shows torque versus twisting angle curves for Group 3. It is noticed that using steel dowels improved the torsional strength and ductility as it resist the induced shear flow due to torsion. All beams in this group showed obvious reduction in twisting angle as well as high increase in torsional strength. This method of strengthening compensates the presence of opening effectively. Figure 17 shows a comparison of torque versus twisting angle curves for Group 4. It improved the torsional strength. Best result for this group obtained for SB30*6 which approaches the behavior of R0. Figure 18 shows torque versus twisting angle curves for Group 5. It is noticed that using carbon fiber plates showed great improvements for the torsional strength, ductility and energy absorption. All beams in this group showed obvious reduction in twisting angle, high increase in ultimate torsional strength as well as high increase in energy absorption. This method of strengthening compensates the presence of large openings effectively. 


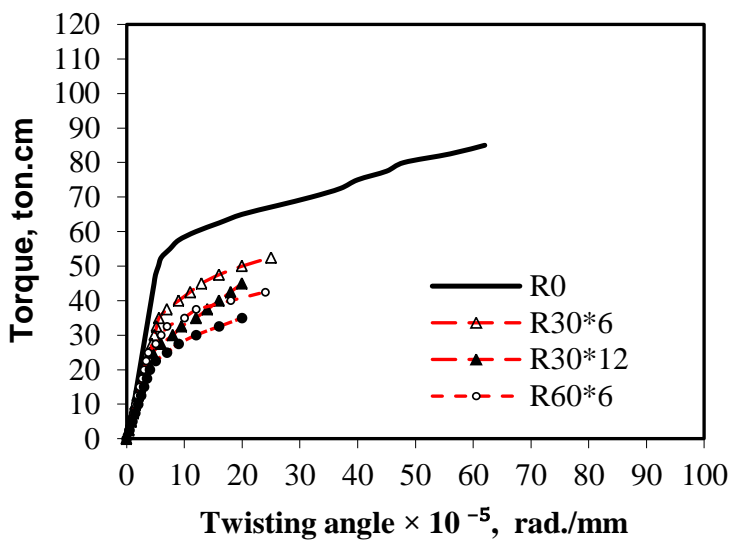

Fig. 14: Torque versus twisting angle for Group 1

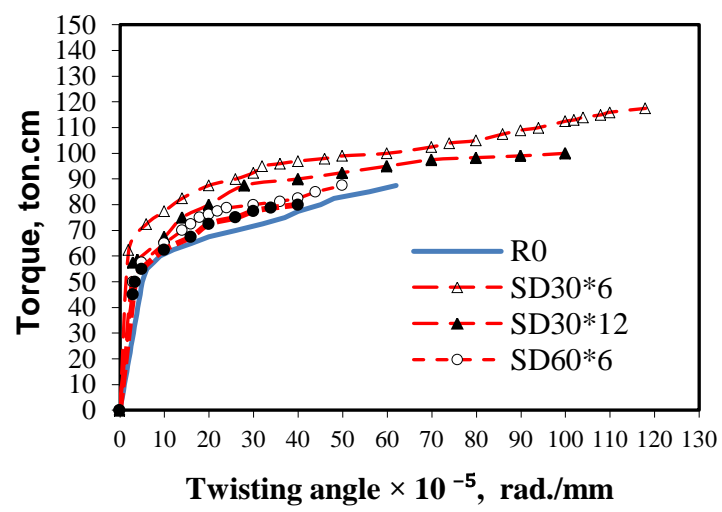

Fig. 16: Torque versus twisting angle for Group 3

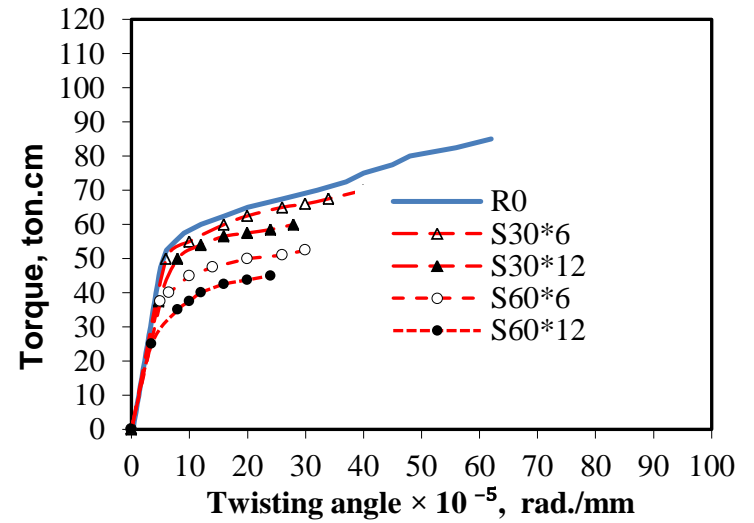

Fig. 15: Torque versus twisting angle for Group 2

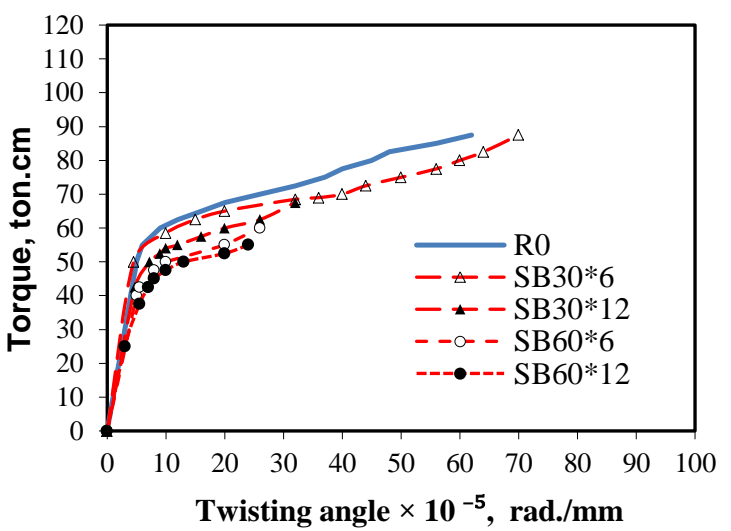

Fig. 17: Torque versus twisting angle for Group 4

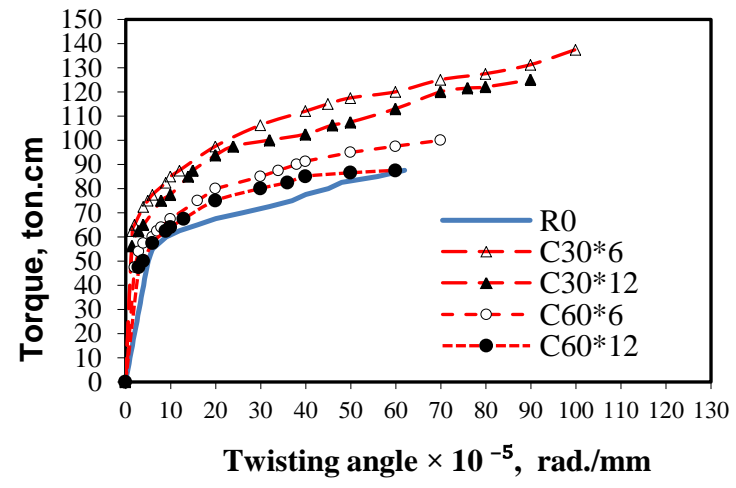

Fig. 18: Torque versus twisting angle for Group 5

\section{CONCLUSIONS}

1- Transvers openings in beams decreases the torsional strength and the reduction depends on the area of the opening.

2- All strengthened techniques improved the results of the torsional strength, ductility, and energy absorption with the corresponding reference specimens.

3- For reference RC beams, R30*6, R30*12, $\mathrm{R} 60 * 6$, and $\mathrm{R} 60 * 12$, ultimate torques were decreased due to openings with respect to beam without opening, R0 by about $43 \%, 51 \%, 51 \%$ and $60 \%$ respectively.
4- The ultimate torques for $\mathrm{S} 30 * 6, \mathrm{SD} 30 * 6$, $\mathrm{SB} 30 * 6$ and $\mathrm{C} 30 * 6$ were increased with respect to the corresponding reference specimen $\mathrm{R} 30 * 6$ by about $40 \%, 138 \%, 76 \%$, and $176 \%$ respectively.

5- The ultimate torques for $\mathrm{S} 60 * 12, \mathrm{SD} 60 * 12$, SB60*12 and C60*12 were increased with respect to the corresponding reference specimen R60*12 by about $23 \%, 131 \%, 57 \%$, and $151 \%$ respectively. 
6- Using dowels in addition to eboxy for fixing the steel plates improved the results effectively in torsion as dowels resist the induced shear flow near the surfaces of the openings. Ultimate torques for $\mathrm{SD} 30 * 6, \mathrm{SD} 30 * 12, \mathrm{SD} 60 * 6$ and $\mathrm{SD} 60 * 12$ were increased with respect to specimens $\mathrm{S} 30 * 6, \mathrm{~S} 30 * 12, \mathrm{~S} 60 * 6$ and $\mathrm{S} 60 * 12$ by about $70 \%, 67 \%, 76 \%$, and $88 \%$ respectively.

7- Specimens SD30*6 and SD30*12 gave better results than the reference beam R0 by about $35 \%$ and $14 \%$ respectively.

8- Using steel box as U shape around the internal sides of opening gave better results for resisting bending stresses than torsional stresses because maximum torsional stresses concentrate on the external layers of the cross section of the beam.

9- Specimens C30*6, C30*12, C60*6 and C60*12 gave better results than the reference beam R0 by about $57 \%, 31 \%, 14 \%$ and $0.0 \%$ respectively.

10- Best results for resisting torsion were obtained by strengthening beams using carbon fiber reinforced polymer CFRP plates in Group 5. The second best results for strengthening is by using steel plates fixed by both eboxy and steel dowels in Group 3.

\section{REFERENCES}

[1] Jithinbose K.J., Thomas J. and Parappattu, N.B., " Effect of Openings in Beams - A Review ", International Journal of Innovative Research in Advanced Engineering (IJIRAE) ISSN: 23492763 Issue 09, Volume 3 (September 2016).

[2] Rezwana B.H., Shaibal, A., Saikat B. and Sharmin R.C., " Effects of Opening on the Behavior of Reinforced Concrete Beam ", IOSR Journal of Mechanical and Civil Engineering (IOSR-JMCE)e-ISSN: 2278-1684,p-ISSN: 2320-334X, Volume 11, Issue 2 Ver. VII (MarApr. 2014), PP 52-61

[3] Egyptian Code of Practice ECP 2032017), "Egyptian Code for Design and Construction of Reinforced Concrete Structures", Ministry of Housing, Utilities and Urban Development, Housing and Building National Research Center HBNRC, Cairo, Egypt, 2017.

[4] ACI Committee 318, "Building Code Requirements for Reinforced Concrete", ACI318R-19, American Concrete Institute, 2019.

[5] Meleka, N.N., Kamal, M.M., Soliman, M.Hand Emam, A.A., "Strengthening of Beams with Large Web Openings in Shear Spans by Using Glass and Steel Fibrous Concrete", Fourth Conference of Egyptian Rural Development, Minoufiya University, 16 September 2003, p.p. 1407- 1430.
[6] Meleka, N.N., Heiza, K.M,., and Elwakad, N.Y., "Shear Strengthening of Self-Consolidating Reinforced Concrete Deep Beam with a Central Opening", Ain Shams Journal of Civil Engineering, ASJCE, Vol. March, 2009.

[7] Mirza, M. S; and McCutcheon, J. 0., "Behavior of Reinforced Concrete Beams under Combined Bending, Shear, and Torsion", ACI Journal, Proceedings V. 66, No. 5, .May 1969, pp. 421427.

[8] Ersoy, U. and Ferguson, P.M., "Behavior and Strength of Concrete L-Beams Under Combined Torsion and Shear", ACJ Journal, Proceedings, 64, December 1967, 797-801. Disc., 65, 477-479.

[9] Nabil A., Meleka N.N., Hieza Kh., Tayel M.A, " State-of-the Art Review: Strengthening of Reinforced Concrete Structures - Different Strengthening Techniques", Sixth International Conference on Nano-Technology in Construction NTC, Cairo, Egypt, 22-24 March 2014.

[10] Chalioris, C.E., "Tests and Analysis of Reinforced Concrete Beams under Torsion Retrofitted with FRP Strips", Proceedings 13th Computational Methods and Experimental Measurements (CMEM), Prague, Czech Republic, 2007.

[11] Meleka, N.N., Heiza, K.M. and Osman, I.M., "Torsional Behavior of Self Compacted Concrete Beams Strengthened by FRP Systems", 1th International Conference: Ninth Conference of Sustainable Environmental Development, Faculty Engineering, Menoufia University, 24-28 March, 2017.

[12] Panchacharam, S. and Belarbi, A., "Torsional Behavior of Reinforced Concrete Beams Strengthened with FRP Composites", Proceedings 1st FIB Congress, Osaka, Japan, 2002, pp.1-10.

[13] Ameli, M. and Ronagh, H.R., "Behavior of FRP Strengthened Reinforced Concrete Beams under Torsion", Journal of Composites for Construction, No.11 (2), 2007, PP.192- 200.

[14] Soluit, A.K, Motawea, A.M. Elsayed K.M. and Shalaby, S.H. "Torsional Behavior of RC Beams Strengthened with Fiber Reinforced Polymer Sheets", Engineering Research Journal

[15] Meleka, N.N., Tayel, M.A. and Ramadan, A.M., "Experimental Evaluation of Advanced Techniques for Repair and Strengthening of Reinforced Concrete Slabs", Alexandria Engineering Journal, Vol. 43, No. 3, May 2004. 
[16] Kamal, M.M, Meleka, N.N., Tayel, M.A., and Mohamed R.M., "Repair and Strengthening of Flat Slabs Using Advanced Materials", Eleventh International Colloquium on Structural and Geotechnical Engineering, Ain Shams University, Faculty of Engineering, Department of Structural Engineering, 17-19 May 2005, pp. E05RC31-1-10.

[17] Meleka N.N., Safan M.A., Bashandy A.A., Abd-Elrazek A.S., " Rehabilitation of Elliptical Parabolic Reinforced Concrete Shells with Openings", ASIAN Journal of Civil Engineering (BHRC) Vol. 14, No. 6, pp.945963, June 2013.

[18] Gobarah,A., Ghorbel, M., and Chidiac, S., "Upgrading Torsional Resistance of RC Beams Using FRP." Journal of Composites for Construction, Mo 6, 2002, pp.257-263.

[19] Meleka N.N., Hieza Kh., Tayel M.A, Nabil A., " Strengthening of Axially Loaded Circular Concrete Columns Using Externally Bonded GFRP Lateral Confinement and Near Surface Mounted Technique", Sixth International Conference on Nano-Technology in Construction NTC, Cairo, Egypt, 22-24 March 2014.
[20] Sika Egypt for Construction Chemicals S.A.E. International, http://www.Sika.com.

[21] Meleka, N.N., Heiza, K.M. and Osman, I.M., "Fracture Behavior, Mode of Failure, and Failure Pattern of RC Beams under Torsion", $1^{\text {th }}$ International Conference: Ninth Conference of Sustainable Environmental Development, Faculty Engineering, Menoufia University, 2428 March, 2017.

[22] Hsu, T.T., "Post-Cracking Torsional Rigidity of Reinforced Concrete Sections", ACI Journal, Proceedings, Vol.70, No.5, May 1973, pp.352360.

[23] Rahal, K. N., and Collins, M. P., "Effect of the Thickness of Concrete Cover on the ShearTorsion interaction - An Experimental Investigation.” ACI Structural. J., No.92, 1995, PP. 334-342. 114, 2007, pp.C102-C119. 